ISBN 978-93-86878-09-0

10th International Conference on Language, Humanities, Education and Social Sciences

(ICLHESS-18)

Bali (Indonesia) Jan. 12-13, 2018

\title{
Employee Cognitive Resource: A Consideration for Employer to Determine Employee Retirement Age
}

\author{
Marina Sulastiana, Rezki Ashriyana Sulistiobudi and Ernie S. Tisnawati \\ Universitas Padjadjaran, Bandung, Indonesia
}

\begin{abstract}
Retirement is one of the issue that acquire attention of researchers in psychology since many years ago. In Indonesia, policy of retirement age was made by the managerial board, based on the legality regulation of Indonesian government.Time to retired defined at 56-58 years old for most of company in Indonesia, and can be different in every company. The policy from employer will determined carefully based on employee ability related to work productivity in variation of age stages. This research aimed to explore and describe the differences employee level of cognitive resource (i.e flexibility thinking, spatial ability, memory span, analytical thinking and attention to detail) at some of age stages.The participants in this research were 270 employees in operational job group from one of transportation service company in Indonesia. The age range of participants was 39-56 years old. The data was collected by objective test as psychological assessment for cognition, Focus Group Discussion (FGD) and secondary document. The data was analyzed in descriptive and inferentially statistics. Data coding also used to analyze qualitative data. We explore state each aspect of cognitive i.e flexibility thinking, memory, analytical thinking and attention to detail. Result show that only attention to details that significantly different from other level age of subgroup. The result of this research had given a reference about retirement age from the psychological perspective, specifically in cognitive function. It can be a useful consideration for employer to maintain the employee's well-being and also keep the stability of company productivity through the clear decision of retirement age limit. Characteristic of work and practical suggestion for management will also discuss in depth to better understanding about the research finding.
\end{abstract}

Keywords: retirement age limit, cognition, operational job group

\section{Introduction}

Discussions on retirement, aging, and its effects on work productivity have been going on for over decades. Under Indonesian Government Regulation, PP Number 45 of 2015, the employee's retirement age limit is set by the government at 56 year old for goverment employee, and 58 year old for State-Owned Enterprises, while starting in 2019 the employee retirement age limit will be adjust to be 57 years old. As stated in Indonesian Law, UU Number 13 of 2003 about employment, it is not definitely clear age of employees will get retired. However, the decision of the retirement age limit usually refers to the prevailing practices within the company, based on employee rights relating to retirement. Therefore, the policy becomes the authority of the company to determine the retirement age of its employees. It can be done by referring to government regulations with consideration on the benefits and productivity of the employees themselves. That is, companies can set the retirement age employees faster or slower than stated in government regulations with certain clear considerations.

In Indonesia, most of the employee retirement age refers to the regulation set by the government. But it can be different among company, if the employee has certain competencies so that they will continued the period to work in company. They get the new employment contract as expert or specific job related to their competencies. Sometimes, senior employees with better knowledge, skill and experience tend to be retained by companies rather than new employees. They are considered more mature, mastered technical skills and understand the work environment better. 
In some types of company, detail and precision of work outcomes become major key of their quality of work. In mass transportation company, both private or state own enterprise, determine that service quality, work precisely and public safety is one of key performance of their company. This leads to the emergence of thinking critically on issues related to work capacity and participation of the older age worker in the workforce. In employer viewpoints, hiring employees to stay worked until the retirement age limit seems maybe quite efficient. They have been familiar with the type of job, work environment, values and regulations in the company. They already know their job better. On the other hand, their endurance and work flexibility was not as good as other younger employees. When the older employees work longer, it can affect their well being. Quality of jobs and working environment need to be considered, because this can make a significant contribution to keep people at work (Villosio, 2008). Reducing the risk of occupational accidents, and reducing physical and mental stress, can improve the health condition of employees, which may be particularly beneficial for the health of the oldest worker (Schalk \& Van Veldhoven et.al, 2010). Furthermore, when employees have to stay at work for a longer period of time, anticipating changes that occur with age might help to manage the working life cycle better. That is all the responsibility taken by management in keeping the well being at work for older worker.

A fundamental aspect of the ageing process is the decline of cognitive abilities. Schaie (1989) shows that cognitive functioning is relatively stable until the fifth decade of life. After this period, the decline becomes apparent and the incidence of cognitive impairments increases sharply with age. At all ages, however, there is large variation across individuals in the level of cognitive performance (Mazonna \& Peracchi, 2012). This suggests that accounting for the different dimensions of cognitive functioning may be important for an analysis of the process of cognitive ageing. One conceptual framework, due to Horn and Cattel (1967) and Salthouse (1985), distinguishes between two types of abilities. The first type, 'fluid intelligence', consists of the basic mechanisms of processing information which are closely related to biological and physical factors, affect by ageing. The second type, 'crystallized intelligence', consists of the knowledge acquired during the life with education, work experience and other life experiences. Unlike fluid intelligence, which is subject to a clear decline as people get older, crystallized intelligence tends to be maintained at older ages and is subject to a lower rate of age-related decline. As argued by Salthouse (1985), dimensions of cognitive functioning such as orientation, memory, fluency and numeracy, are generally based on different combinations of fluid and crystallized intelligence.

Recent research in neuroscience (see van Praag et al. 2000 for a review) has questioned the idea that agerelated cognitive decline is inevitable and fixed. Although neural plasticity is reduced in old age, it remains more substantial than previously recognized. In their comprehensive review, Hertzog et al. (2008) describe how the age-profiles of cognitive abilities can differ over the life span in response to various types of behavior. One of important factors that may affect is the characterstic of occupational and education (Adam et al. 2006; Rohwedder and Willis 2010; Banks and Mazzonna, 2011). Based on their findings, job characteristics can affect the declining of the cognitive function. Several studies on employees in Europe stated that low-complexity occupations have been identified as risk factors for age-related cognitive decline (Capurso et al., 2000). In a recent study, Schooler et al. (1999) showed that complex intellectual work increases the cognitive functioning of older workers.

The differences in company's core business will have an impact on the necessity which of cognitive aspects to be considered in determining one's optimal age at work. In companies who run business in mass transportation services, will be crucial to include the aspects of cognitive ability as a major requirement achieving standard quality of work and employee's work fastness. They are memory span, flexibility thinking, analytical thinking, attention to detail and spatial abilities. Memory span is used to recalling work instructions, listing the tools equipment before start to work. Flexibility thinking is one's initial potential to be able to find alternative problem solutions at work. Analytical thinking is used in analyze the situation, determining the core of the problem so as to find an alternative solution through flexibility thinking. Spatial ability is necessary for employees whose work involves equipment so they can imagine 2D (2 dimension) design images into 3D (3 dimension). Attention to 
detail is crucial for employees who need to maintain their quality of work, especially on tasks that require zero fault because it will impact on their service performance and community safety.

Based on explanation above, we intend to answer and explore the research question below :

1. Is there any difference in cognitive aspects among employee's level of age group?

2. Is there any difference in cognitive aspects on managerial level compared to staff level ?

\section{Methods}

This study used cluster non random sampling technique. Sampling based on work area, referring to job group (operational division). We get 270 employee participated in this cross-sectional study. Then, we select and calculate number of sampling to each stages of employee age. We have made a 9 stages, they are employee in 39-40 years old, 41-42, 43-44, 45-46, 47-48, 49-50, 51-52, 53-54 and 55-56 years old. The grouping of the employee was almost equal in number, it is describe in Figure 1 below. Furthermore, we analyze the result both in operational staff level and managerial level in order to get some specific finding based on different characteristics of work in its two level of job position.

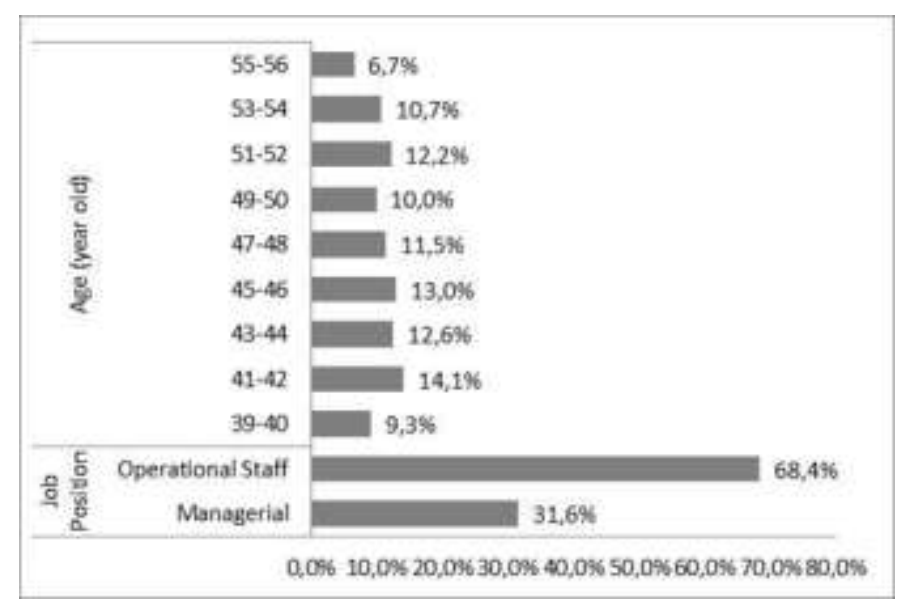

Fig. 1: Demographic Data of Respondent

Measuring the degree of cognitive aspects of respondents, we used established objective intelligence test in Indonesia, TIKI Long Form and Intelligence Structure Tes (IST-70). The result score converted to the group norms of people in Indonesia based on range of age and educational background (social science or natural science). Qualitative and quantitative analysis was used in this study. Quantitative analysis using inferential statistics dan descriptive statistics. Descriptive statistics describe the mean, median and mode in the form of charts and tables. Then, we performed the test of normality distribution of the data for each aspects of cognitive ability. The Kolmogorov-Smirnov test and the Shapiro-Wilk's W test determine whether the underlying distribution is normal. We also include an evaluation of the normality of histograms or Q-Q plots as these are more appropriate for assessing normality in larger sample (above one hundred of respondents).Then, we get that all the data was normally distributed. Therefore, we performed One Way Anova to test how the data differ between age groups for each aspects of cognitive function. We also conducted the Pearson Correlation to justified relationship among characteristic of work as manager and staff level to cognitive abilities as resource.

\section{Result \& Discussion}

\subsection{Result}

As we seen in Table 1, almost all cognitive aspects of respondent in managerial level was higher than staff level i.e flexibility thinking, analyical thinking, attention to detail and spatial ability. In contrast to the other 4 aspects, mean value of memory span does not higher than staff level. Based on descriptive data below, the 
difference between managerial and staff level is only about 1-2 scores, except on attention to detail. Range score on attention to detail narrower than other aspects, minimum score 0 and maximum score 30.

TABLE I: Descriptive Analysis

\begin{tabular}{llcc}
\hline Job Position & Cognitive Aspects & Mean & Standard Deviation \\
\hline Managerial Level & Memory span & 96,20 & 5,66 \\
& Flexibility thinking & 99,45 & 8,60 \\
& Analytical thinking & 98,75 & 4,98 \\
& Attention to detail & 6,62 & 4,81 \\
& Spatial ability & 98,41 & 8,57 \\
Operational Staff & Memory span & 97,02 & 7,82 \\
& Flexibility thinking & 92,96 & 6,07 \\
& Analytical thinking & 95,73 & 6,31 \\
& Attention to detail & 4,74 & 4,54 \\
& Spatial ability & 97,37 & 8,33 \\
\hline
\end{tabular}

Table 2 describe that only Attention to Detail as cognitive aspects has significant differences among level of age group of respondent (p-value 0,000). It only occured in Staff Level only, not at Managerial Level. In Managerial Level, there is no aspect of cognitive ability that has a significant different score, either lower or higher when compared with other age levels. There is no distinction of memory span, flexibility thinking, analytical thinking, attention to detail and spatial ability in various range of age on managerial level. Figure 2 shows that the age 39-40 and 41-42 years old employee are the most optimum in working with details. As shown in Figure 2, 53-54 years old employee has the lowest ability to focus on details if compared to another younger employee in different age group.

TABLE II: Inferential Statistic Result - Differences on Age Level

\begin{tabular}{llllll}
\hline Job Position & Cognitive Aspects & $\begin{array}{l}\text { Mean } \\
\text { Square }\end{array}$ & F & df & $\begin{array}{l}\text { Sig.(2- } \\
\text { tailed) }\end{array}$ \\
\hline Managerial Level & Memory span & 70,000 & 0,940 & 8 & 0,489 \\
& Flexibility thinking & 36,546 & 1,157 & 8 & 0,336 \\
& Analytical thinking & 19,907 & 0,786 & 8 & 0,616 \\
& Attention to detail & 30,842 & 1,378 & 8 & 0,220 \\
Staff Level & Spatial ability & 54,547 & 0,722 & 8 & 0,672 \\
& Memory span & 77,288 & 1,279 & 8 & 0,258 \\
& Flexibility thinking & 65,544 & 1,845 & 8 & 0,072 \\
& Analytical thinking & 71,516 & 1,867 & 8 & 0,068 \\
& Attention to detail & 86,288 & 4,924 & 8 & $0,000^{*}$ \\
& Spatial ability & 70,709 & 1,019 & 8 & 0,424 \\
\hline
\end{tabular}

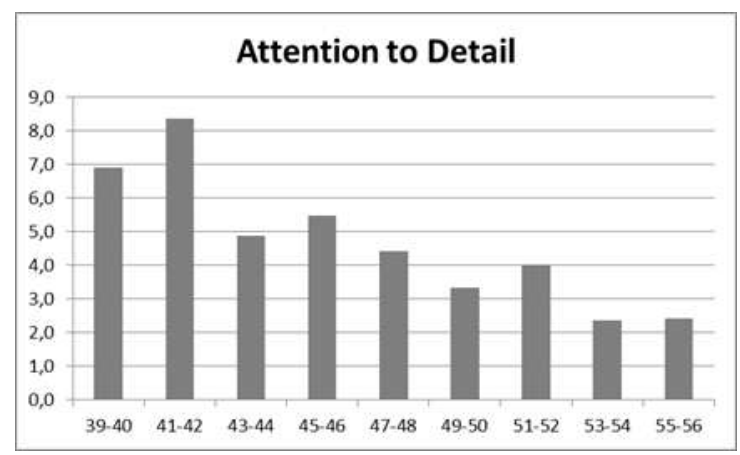

Fig. 2: Mean Score in Attention to Details

Figure 2 shows that the mean score tends to decline from one age group to the older age group. The highest mean score is at age 41-42 years old and lowest in 53-54 years old. In this study the result shows that aging factors is the primary cause of the difference, under the assumption that other individual factors were similar. 
TABLE III: Mean Differences in Age Level

\begin{tabular}{|c|c|c|c|c|c|c|}
\hline \multirow[t]{3}{*}{ (I) age } & \multirow[t]{3}{*}{$\begin{array}{l}(\mathrm{J}) \\
\text { age }\end{array}$} & \multirow{3}{*}{$\begin{array}{c}\text { Mean } \\
\text { Difference } \\
(\mathrm{I}-\mathrm{J})\end{array}$} & \multirow[t]{3}{*}{$\begin{array}{l}\text { Std. } \\
\text { Error }\end{array}$} & \multirow[t]{3}{*}{ Sig. } & \multicolumn{2}{|c|}{$\begin{array}{l}\text { 95\% Confidence } \\
\text { Interval }\end{array}$} \\
\hline & & & & & Lower & Upper \\
\hline & & & & & Bound & Bound \\
\hline \multirow{8}{*}{$\begin{array}{l}39-40 \\
\text { (years old) }\end{array}$} & $41-42$ & $-1,30743$ & 1,14644 & ,255 & $-3,5651$ & ,9502 \\
\hline & $43-44$ & 1,33088 & 1,16616 & ,255 &,- 9656 & 3,6274 \\
\hline & $45-46$ & 60985 & 1,17345 & 604 & $-1,7010$ & 2,9207 \\
\hline & $47-48$ & 2,28629 & 1,18929 & ,056 &,- 0557 & 4,6283 \\
\hline & $49-50$ & $3,53241^{*}$ & 1,22712 & ,004* & 1,1159 & 5,9490 \\
\hline & $51-52$ & $4,12500^{*}$ & 1,18115 &, $001 *$ & 1,7990 & 6,4510 \\
\hline & $53-54$ & $4,43534^{*}$ & 1,20705 &, $000 *$ & 2,0583 & 6,8124 \\
\hline & $55-56$ & 2,40278 & 1,36387 &, $040 *$ &,- 2831 & 5,0886 \\
\hline
\end{tabular}

The study found that Attention to Detail significantly different among the age groups. Then we conducted the One Way Annova Test. The test is performed to shows that the means on several age group are different. Based on these results the score for Attention to Details show the significant mean differences on level of age group 49-50, 51-52, 53-54 and 55-56 years old. Mean score differences between 39-40 years old and 49-50 years old is 3,532; 39-40 years old and 51-52 is 4,125; $39-40$ and $53-54$ is 4,$435 ; 39-40$ and $55-56$ is 2,402.

TABLE IV: Inferential Statistic Result - Correlation Between Cognitive Aspects and Level of Position (Managerial and Staff Level)

\begin{tabular}{lcccccc}
\hline \multicolumn{1}{c}{ Cognitive Aspects } & \multicolumn{7}{c}{ Coeff. Correlation } \\
\multicolumn{1}{c}{ Manager - Staff } & 1 & 2 & 3 & 4 & 5 & 6 \\
\hline Memory span & 1 & & & & & \\
Flexibility thinking &, $355^{* *}$ & 1 & & & & \\
Analytical thinking & $391^{* *}$ &, $738^{* *}$ & 1 & & & \\
Attention to detail &, $349^{* *}$ &, $244^{* *}$ &, $233^{* *}$ & 1 & & \\
Spatial ability &, 090 &, $213^{* *}$ &, $208^{* *}$ &, 110 & 1 & \\
Level of Position &,$- 140^{*}$ &,$- 249^{* *}$ &,$- 234^{* *}$ &,$- 188^{* *}$ &,- 058 & 1 \\
\hline
\end{tabular}

Then, we conducted the Pearson Product Moment test. It is useful to determine coefficient correlation between position of manager and staff to cognitive ability. As stated in Table 4, we can conclude that almost all cognitive abilities tested was correlate significantly with level of position at work (manager or staff) except the spatial ability. The higher the level of position, related to the higher ability for thinking and processing the information. Figure 3 describe comparison between manager and staff on each aspects of cognitive ability. As we seen, the managerial level tend to show the higher mean score than the staff level, except in spatial ability.
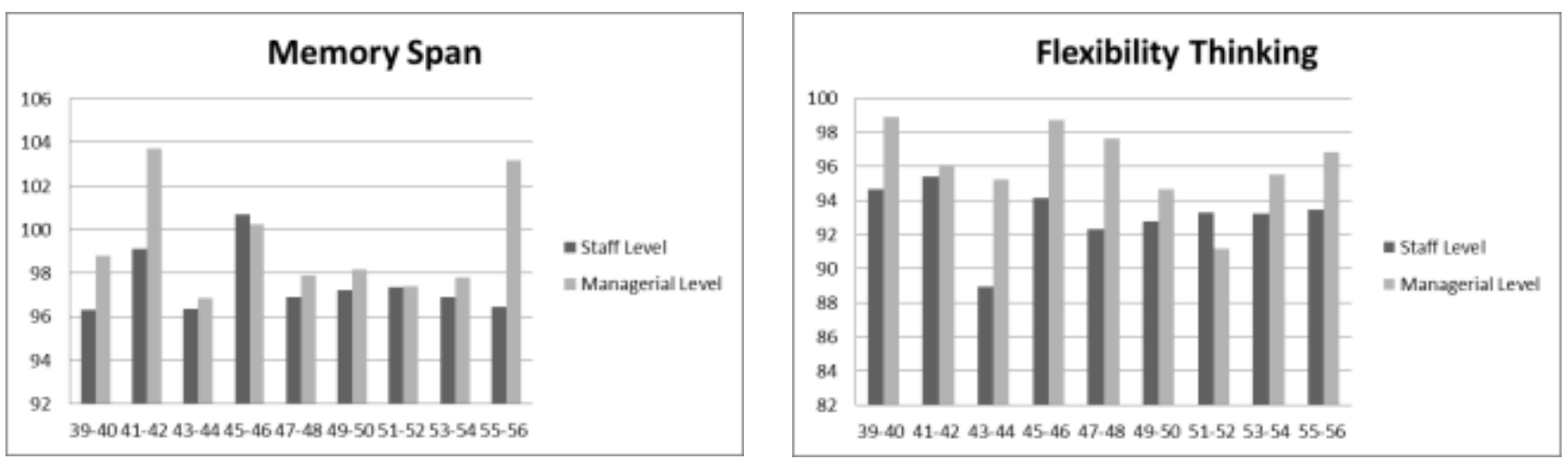


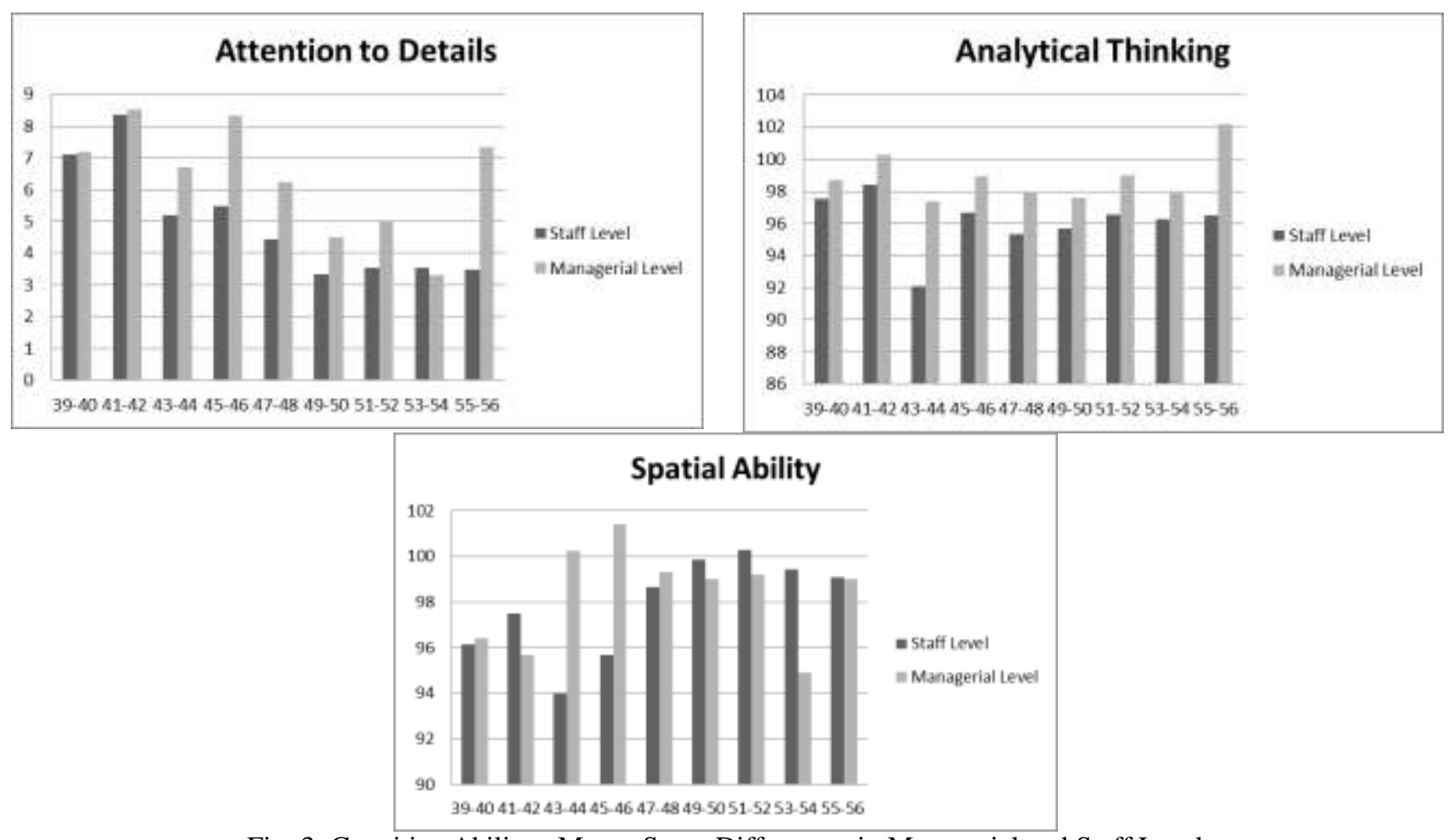

Fig. 3: Cognitive Ability - Means Score Differences in Managerial and Staff Level

\section{Discussion}

Through this study, we found that Attention to Detail has a significant differences in some of group level of age. Attention to Details is the ability to achieve thoroughness and accuracy when accomplishing a task (performance.edu.au, 2017). Having ability in attention to details expected the employees able to minimize work errors. They should be able to double check the work, paying close attention to the work being done. If connected with the core business of the company, then with the attention to detail as one of the ability so it can make work become more efficient an effective. This difference only occurs in the group of staff level only. Otherwise, in the group of managerial level, there is no cognitive aspect showed significant differences in each age level of subgroup.

This finding important for employer to always be aware when their 53-54 years old employees working on the type of task that requires high of precision. Anticipating risk that may arise, employees on that age level can be placed on jobs that are not too risky and safe condition. Concern from employer is important. Give them task that do not require very high accuracy. Alternatively, they can also assisted with younger employees to minimize work errors. But, if this is the abilities very crucial for the business of the company, or as ability key of the requirement task of work, then it can be a consideration for employer to make a decision for employee retirement age, especially in operational staff, regarding the type of their task.

At the manager level, almost all aspects of cognitive that have been measured (flexibility thinking, memory span, attention to details, analytical thinking and spatial abilty) show higher scores than respondents at the staff level. There is no difference scores in the younger to the older age group. It is showed that manager's level of cognitive abilities were relatively similar at the age 39-40 years old until 55-56 years old. This condition illustrate that the complexity of work at the manager level also helps them to maintaining the cognitive abilities as a resource. It is also proved by the results of inferential statistics analysis. It showed that position in managerial level and staff level correlate with almost aspects of tested cognitive ability, except spatial ability. As manager, they keep their roles in managerial proces such as planning, organizing, leading and controlling (Schemerhorn, 2013). Doing managerial roles will be more used in thinking capability than just doing the 
technical operational or day to day routine work. Schooler et al. (1999) showed that complex intellectual work increases the cognitive functioning of older workers. When it always used in facing complex problem at work, then it won't be decrease significantly in older worker. We can say that manager level has the longer period of work due to cognitive abilities.

Furthermore, the findings show that significant differences score occured between 39-40 years old and 49-50 years old to 55-56 years old. The biggest score differences occur at the 53-54 years old. It means that, the lowest score of attention to detail is at 53-54 years old, when it is compared to the employees 39-40 years old, only in staff level. Considering the lack of Attention to Details have a big impact on service performance and work safety, this findings can be use to determine age of retirement on staff level in operational jobs. Understanding the whole concept of aging in cognitive ability should be analyzed by the individual and environment factor. Stern (2002), stated that individuals have different levels of cognitive reserve and a higher level allows them to prevent or slow down the process of aging. Then, environment describe the important factors in this process are education, occupational and retirement choices (Adam et al. 2006, Bonsang et al. 2010, Rohwedder and 1 Willis 2010).

This study is an early exploration of cognitive aspects in determining the optimal age for employees to retire. Considering the job characteristics and core business of the company is important. Thus, it is expected to obtain an optimal productive age determination model for employees based on the demands and characteristics of each jobs. The next development of the research still open widely. Longitudinal research methods can be more precisely define the declining process of older worker in each stages of age. Others demographic aspects should be tested through analysis quantitative to determine the declining tendency of cognitives aspects from time to time. Both individual and and environmental factor must be included into the research so it can describe the dynamics comprehensively.

\section{Acknowledgement}

This research collaborated with BUMN (State Owned Enterprise's/SOE's) Centre of Excellence (BCE) Universitas Padjadajaran.

\section{References}

[1] Adam S., Bay C., Bonsang E., Germain S., and Perelman S. (2006), "Occupational activities and cognitive reserve: A frontier approach applied to the Survey of Health, Ageing and Retirement in Europe (SHARE)." CREPP WP 2006/05, University of LiegeSchalk, R., Van Veldhoven, M., De Lange, A. H., De Banks J., and Mazzonna F. (2011), "The effect of education on old age cognitive abilities: Evidence from a regression discontinuity design." Economic Journal, forthcoming.

[2] Gustafsson, J. E., \& Undheim, J. O. (1996). Individual differences in cognitive functions

[3] Hertzog C., Kramer A.F., Wilson R.B., and Lindenberger U. (2008), "Enrichment effects on adult cognitive developments. Can the functional capacity of older adults be preserved and enhanced?" Psychological Science in the Public Interest, 9: 1-65.

[4] Horn J.L., and Cattell R.B. (1967), "Age differences in fluid and crystallized intelligence." Acta Psycho-logica, 26: $107-129$.

[5] Mazzonna, F., \& Peracchi, F. (2012). Ageing, cognitive abilities and retirement. European Economic Review, 56(4), 691-710.

[6] Rohwedder S., and Willis R. (2010), "Mental retirement." Journal of Economic Perspectives, 24: 1-20.

[7] Salthouse T.A. (1985), A Theory of Cognitive Aging. Amsterdam, North-Holland.

[8] Schermerhorn, J. R. (2013). Introduction to management. John Wiley \& Sons. 
[9] Schalk, R., Van Veldhoven, M., De Lange, A. H., De Witte, H., Kraus, K., Stamov-Roßnagel, C., ... \& Bertrand, F. (2010). Moving European research on work and ageing forward: Overview and agenda. European Journal of Work and Organizational Psychology, 19(1), 76-101

[10] Schooler, C., Mulatu, M. S., \& Oates, G. (1999). The continuing effects of substantively complex work on the intellectual functioning of older workers. Psychology and Aging, 14, 483-506.

[11] Van Praag, H., Kempermann, G., \& Gage, F. H. (2000). Neural consequences of enviromental enrichment. Nature Reviews Neuroscience, 1(3), 191-198.

[12] Witte, H., Kraus, K., Stamov-Roßnagel, C., ... \& Bertrand, F. (2010). Moving European research on work and ageing forward: Overview and agenda. European Journal of Work and Organizational Psychology, 19(1), 76-101.

http://www.performance.edu.au/blog/how-can-you-develop-your-attention-detail 